\title{
PERTENCIMENTO E IDENTIDADE, TERRITORIALIDADE E FRONTEIRA ENTRE OS CHIQUITANOS NO BRASIL E NA BOLIVIA ${ }^{1}$
}

\author{
JOANA APARECIDA FERNANDES SILVA ${ }^{2}$
}

$U F G$

\begin{abstract}
RESUMO: Pretende-se refletir, a partir da história do povo Chiquitano, originalmente um conjunto de mais de vinte etnias que foram aldeadas pelos jesuítas na missão de Chiquitos, elementos de sua identidade e etnicidade contemporâneas. A proposta que se apresenta é a de entender como se situam atualmente as identidades, relacionadas com as territorialidades experienciadas na Bolívia e no Brasil, uma vez que este povo está atualmente cindido parcialmente pelo fato de terem sido fracionados em duas partes a partir da divisão dos estados nacionais. O fato de viverem em um ou outro país provoca diferentes experiências e proposições identitárias; no entanto, até a década de 1980, a fronteira entre os dois países, ainda não totalmente institucionalizada, permitia um trânsito de um para outro lado, mas para além disso, permitia relações sociais e manutenção de redes de parentesco. Como se desenham as identidades atualmente, na diversidade territorial $e$ histórica? Como estão desenhadas as territorialidades dos Chiquitanos na Bolívia e no Brasil se as políticas indigenistas são distintas? Como ocorrem as autoidentificações, sendo que há distintos conceitos para "índios" - aqui, povos indígenas e, na Bolívia, "campesino" ou "pueblos originales"? De que maneira o reconhecimento oficial da etnicidade dos Chiquitanos no Brasil trouxe novos elementos suscitadores de conflitos? Estas são questões que se pretende responder neste artigo.
\end{abstract}

PALAVRAS-CHAVE: identidade; fronteira; nacionalidade; Chiquitanos.

ABSTRACT: It is intended to reflect, from the history of the people Chiquitano, originally a set of more than twenty ethnic groups that were aldeadas by Jesuits in the Chiquitos mission, elements of contemporary identity and ethnicity. The proposal presented is to understand how identities are situated today relating to the territoritalities experienced in Bolivia and Brazil, since these people are currently split because the division of national states. The fact that they live in one country or in another causes different experiences and propositions of identity. However, until the 1980s the frontier between the two countries was not yet fully institutionalized, and it was possible a transit to and fro, and this freedom allowed maintenance of social relations and kinship networks. How are the identities currently in territorial diversity

\footnotetext{
${ }^{1}$ Este artigo foi apresentado no VI Congresso do Ceisal, realizado em Toulouse, no ano de 2010. Posteriormente, com algumas modificações, foi apresentado no "(Re)pensando coletivos tradicionais na América Latina", realizado na UFRGS, em março de 2012.

2 A autora é professora associada na Universidade Federal de Goiás. Seu mestrado foi realizado na Unicamp, quando estudou projetos de desenvolvimento comunitário executados pela Funai entre os Guarani-Kaiowá. Seu doutorado na USP, em Antropologia Social, versou sobre camponeses do Pantanal mato-grossense. Após 1998, voltou a pesquisar populações indígenas, e seu tema de pesquisa tem sido, desde então, identidade e fronteira entre os Chiquitanos.
}

Espaço Ameríndio, Porto Alegre, v. 6, n. 1, p. 119-137, jan./jun. 2012. 
JOANA APARECIDA FERNANDES SILVA - Pertencimento e identidade, territorialidade...

and historical? How they configure their territoritalities Chiquitanos in Bolivia and Brazil if the indigenous policies are different? How the self-identifications occur if there are different concepts for "Indians" - here and Bolivia indigenous "peasant" or "pueblos originales"? How the official recognition of ethnicity in Brazil Chiquitanos brought new elements that caused conflicts? These are questions we intend to answer in this paper.

KEYWORDS: identity; nacionality; frontier; Chiquitanos.

\section{Apresentação}

No Brasil os Chiquitanos estão localizados em Mato Grosso, na sua porção sudoeste, em regiões próximas à fronteira com a Bolívia. Há uma variedade de estabelecimentos Chiquitanos; aldeias (localmente identificadas como "comunidades de bugres"), agrupamentos em beiras de estradas (resultante de processos de expulsão de terras tradicionais antes do reconhecimento da FUNAI - Fundação Nacional do Índio), estabelecimentos juntamente com os destacamentos militares. Há, também, uma população de Chiquitanos urbanizados nas cidades de Porto Espiridião, Cáceres e Vila Bela da Santíssima Trindade, cujo número se desconhece.

$\mathrm{Na}$ Bolívia eles vivem na Gran Chiquitania, nas províncias de Ñuflo de Chávez, Chiquitos, Ángel Sandoval e Jose Miguel de Velasco, todas no departamento de Santa Cruz. Sua população estimada neste país é de 44 mil pessoas, enquanto no Brasil, com exceção da população urbana, é de cerca de duas mil pessoas ${ }^{3}$.

Há, aqui, uma situação de extrema complexidade sociocultural e histórica onde se aliam diferenças de nacionalidades, além de que, em um tempo pretérito, houve uma multiplicidade de povos, cujas singularidades foram anuladas pelo regime jesuítico.

As regiões de fronteira internacional são espaços de intensa convivência intercultural e de diferenças étnicas, sociais, econômicas e políticas. Se as fronteiras nacionais poderiam sugerir uma fixidez, u m local de separação de nações, de povos, Roberto Cardoso de Oliveira

\footnotetext{
${ }^{3}$ Entre outros estudiosos, quero destacar Cynthia Radding (2006), responsável por um estudo aprofundado sobre a identidade dos Chiquitanos ao longo da história, e Charupá (2006 e 2008), pela pesquisa sobre a constituição étnica e territorial da Missão de Chiquitos.
}

Espaço Ameríndio, Porto Alegre, v. 6, n. 1, p. 119-137, jan./jun. 2012. 
JOANA APARECIDA FERNANDES SILVA - Pertencimento e identidade, territorialidade...

(2005) observa que nos espaços transnacionais há um efervescer de relações étnicas e culturais. Pode-se acrescentar que há uma especificidade nesta situação, pois há muitas contingências nestas relações, fortemente marcadas por políticas de estados nacionais, em relação à língua, cultura, territorialidade, políticas indigenistas, além, é claro, do compartilhamento intercultural.

Roberto Cardoso de Oliveira (2005, p. 14) também enfatizou que a fronteira é um local privilegiado de investigação porque nesses locais há uma situação socioeconômica muito complexa em virtude da diversidade cultural aí presente. Os espaços de fronteira, transnacionais, abrigam modalidades de convivência que merecem ser estudadas e há diversas pesquisas bastante desenvolvidas sobre povos indígenas em fronteiras nacionais, experimentando realidades e histórias distintas, como é o caso dos estudos apresentados no livro organizado por Roberto Cardoso de Oliveira e Stephen Baines (2005).

Como espaço transnacional, podemos definir um espaço cosmopolita não metropolitano (APPIAH, 1992), com fluxos migratórios, costumes e tradições compartilhados, além de práticas econômicas e religiosas comuns. A região que se deseja abordar abrange a Bolívia e - Brasil, a partir das fronteiras situadas em Mato Grosso e na província de Velasco, na Chiquitania, pelas localidades de San Inácio, San Miguel, San Rafael, San José de Chiquitos, Santa Ana de Velasco, também conhecida como circuito missional 4 .

São regiões subalternas ou periféricas em ambos os países, porém, com uma vitalidade particular formada, sobretudo na Bolívia, pela forte memória da presença jesuítica, que "costura" a região e alimenta uma identidade, e pela força da presença de Chiquitanos. Por outro lado, o comércio de produtos brasileiros industrializados (pilhas, biscoitos e guloseimas, cigarros, refrigerantes, bolsas, calçados, roupas etc), a influência das músicas brasileiras e dos restaurantes de donos brasileiros na parte boliviana e a política do governo de Mato Grosso e do governo de Velasco, como uma tentativa de trazer o progresso para a região, poderão inaugurar uma nova forma de

\footnotetext{
${ }^{4}$ Uma das primeiras estudiosas, no Brasil, da Missão de Chiquitos foi Denise Maldi Meireles (1989), que também produziu um relatório em que vistoriou a presença de Chiquitanos na Fazenda Nacional de Casalvasco (1985). Estes dois trabalhos são essenciais para o entendimento da situação dos Chiquitanos no Brasil.
} 
JOANA APARECIDA FERNANDES SILVA - Pertencimento e identidade, territorialidade...

subalternização. Ou seja, a província de Velasco como um espaço periférico em relação à Santa Cruz de La Sierra será relativamente modificado em virtude da influência brasileira e sofrerá, provavelmente, o mesmo processo vivido pelos Chiquitanos em Mato Grosso a partir da década de 70, com a intensificação da ocupação capitalista, quando empresas agropecuárias recém-chegadas expulsaram comunidades indígenas inteiras.

A região da fronteira da Bolívia com o Brasil, além de um lugar de passagem para um ou outro país, é também um espaço de vivências particulares prenhe de significados. Alguns tipos de negócios levados por proprietários de restaurantes, lojinhas e mercados são alimentados justamente pelo local de passagem que se constitui a fronteira; pessoas, grupos e mesmo viajantes de ônibus neste cruzamento de limites buscam alimentos, por vezes cambiar moeda, fazer compras etc. San Mathias, por exemplo, já na Bolívia, a cerca de $3 \mathrm{~km}$ da fronteira, é ponto obrigatório dos ônibus que adentram a Bolívia vindos de Cáceres, no Brasil, pois oferece esses serviços.

Ao mesmo tempo em que há certa indistinção, há uma diferença muito grande. O português e o espanhol são mutuamente compreensíveis e não raro o orador da fronteira é bilíngue, mas já é possível perceber que é outro país. As construções dos Chiquitanos seguem os mesmos padrões em ambos os lados e percebe-se uma certa uniformidade cultural. São casas com dois quartos separados por uma área que liga a ambos; este é um padrão recorrente e que se observa até, pelo menos, em San Inácio de Velasco. As fisionomias também são muito parecidas. Quanto a San Mathias, major Frederico notou

Uma velha Chiquitana saúda-nos, perto de um paul. Penetramos numas das ruas, meio oculta pelas árvores das chácaras, entre cercas e currais. Grupos de mulheres curiosas nos olham de dentro dos ranchos. Feições amáveis de moças Chiquitanas se entremostram nas janelas. (...) São Matias é antes um pueblo de Chiquitos. Os collas (côlhas) não passam, talvez, de dez famílias (RONDON, 1936, p. 198).

A fronteira Bolívia-Brasil também tem uma aura de perigo. Região de percursos do tráfico de cocaína, de ladrões de caminhão. 
JOANA APARECIDA FERNANDES SILVA - Pertencimento e identidade, territorialidade...

Terra de ninguém, incontrolável pelo exército brasileiro, sem equipamentos e veículos, e frágil porque guardada por militares bolivianos, por vezes meninos de apenas 16 ou 17 anos. Os pontos guardados por um ou outro lado são exatamente isso: alguns pontos no continuum da fronteira. Não há como controlar militarmente uma linha quase imaginária, com pequenas estradas vicinais que formam uma capilaridade entre ambos países, permitindo o ir e vir.

A língua dos Chiquitanos, no Brasil chamada de linguará ou, em alguns casos, de anenho, é conhecida na Bolívia como Chiquitano, ou besuro. Aqui é uma língua falada, e é mais conhecida pelos Chiquitanos mais velhos. Já no país vizinho, é falado em muitos lugares da Chiquitania, ou seja, nas províncias onde vivem os Chiquitos.

\section{Metodologia}

Os dados apresentados foram levantados em várias viagens de campo, no contexto do projeto de pesquisa "Identidade, Nacionalidade e Fronteira entre os Chiquitanos", como parte do grupo de pesquisa ERENA (Etnicidade, Região e Nação). Inicialmente o envolvimento com os Chiquitanos ocorreu em virtude da passagem do gasoduto BrasilBolívia em suas terras. Os primeiros estudos sobre eles tiveram o objetivo de trazer informações para a FUNAl sobre este povo, que, nos idos 1998, período das obras da ENROLL na porção matogrossense do gasoduto, eram muito esparsas. Pouca certeza havia se nesta região havia ou não algum povo indígena. Posteriormente iniciei o projeto de pesquisa mencionado e várias viagens de pesquisa foram realizadas na área de interesse, mas foram centradas em duas aldeias, Fazendinha e Acorizal (SILVA et al. 1998).

O esforço investigativo incidiu sobre essas duas aldeias por um motivo bem exterior à motivação inicial da pesquisa acadêmica: Fazendinha e Acorizal são vizinhas ao Destacamento Militar de Fortuna e uma denúncia anônima feita à FUNAl de Cuiabá informou que os moradores seriam expulsos no prazo de três semanas. Esta era uma repetição de um processo que já havia sido verificado durante os 
JOANA APARECIDA FERNANDES SILVA - Pertencimento e identidade, territorialidade...

trabalhos preliminares a propósito do gasoduto, ou seja, de uma constante expulsão de comunidades (como são chamadas localmente) de Chiquitanos de suas terras tradicionais para beiras de estradas vicinais ou para centros urbanos próximos. Neste momento fui envolvida novamente com o problema das terras deste povo e coordenei um grupo de trabalho para identificação de uma área que veio a chamar-se Portal do Encantado (SILVA, 2002).

Inicialmente os Chiquitanos não se identificavam como tais e muitas vezes a simples menção a esse nome ou a referência a um vocabulário mínimo da língua deixava algumas pessoas constrangidas. A população regional os chamava de bugres e eles eram extremamente valorizados por serem praticamente os únicos trabalhadores braçais nos municípios de Cáceres, Porto Espiridião e Vila Bela; os homens eram vaqueiros, cuidavam de pastos, formavam fazendas e as mulheres trabalhavam como domésticas. Essa situação mudou substancialmente após a identificação da área indígena.

Esse processo de identificação de terras acirrou um conflito que era latente e encoberto pela quase invisibilidade dos Chiquitanos e pela extrema necessidade deles como mão de obra. Como existem outras dez ou doze comunidades de Chiquitanos e como a FUNAl já havia designado em 2002 ou 2003 novos grupos de trabalho para identificação de outras áreas, eclodiu um conflito - que estudei em Silva (2008) - capitaneado por políticos locais buscando afirmar que tratavase de bolivianos e não de índios, e que a indianidade deles era invenção da FUNAI e de uma antropóloga (no caso, a autora deste artigo).

Desta maneira, os temas da identidade, da fronteira e da nacionalidade estiveram o tempo todo presentes como importantes nortes para entender as relações entre Chiquitanos e a sociedade abrangente. Durante as pesquisas de campo ocorridas tanto no bojo de algum trabalho relacionado com a FUNAI e com problemas de terra, como nas viagens com um cunho mais investigativo do que prático, estes temas sempre foram muito fortemente presentes 5 .

Nas pesquisas de campo utilizou-se o procedimento de

\footnotetext{
${ }^{5}$ Um desdobramento ainda a ser estudado foi uma divisão interna em Acorizal de algumas famílias que não desejam ser identificadas como indígenas.
}

Espaço Ameríndio, Porto Alegre, v. 6, n. 1, p. 119-137, jan./jun. 2012. 
observação participante, combinada com entrevistas abertas com perguntas organizadas em torno do eixo central, acrescidas com um roteiro que buscava entender a territorialidade e a história dos Chiquitanos, uma vez que inicialmente não havia outros estudos realizados, com exceção de um relatório de Maldi (1995), importantíssima pista sobre inúmeros enigmas que então cercavam este povo.

Logo ficou claro que não seria possível entender os temas propostos se não houvesse um conhecimento da Bolívia, onde vive a maioria dos Chiquitanos. Algumas viagens de campo, bem curtas, foram realizadas e tiveram mais um cunho exploratório do que características de pesquisa de campo propriamente ditas. A primeira delas foi basicamente turística, quando visitei o chamado circuito missional, na Chiquitania; os antigos aldeamentos mais conhecidos foram visitados e foi possível confirmar algumas das redes apontadas pelos Chiquitanos no Brasil, que se relacionam mais intensamente com os locais de Santa Ana e de San Inácio. Na Chiquitania foi possível verificar uma identidade muito fortemente ligada à região e que parece constituída a partir da herança arquitetônica jesuítica.

O diálogo entre a antropologia e história foi fundamental, pois, no caso estudado, a história, enquanto temporalidade, se fazia presente todo o tempo. Não era possível realizar um corte sincrônico e simplesmente partir para a pesquisa de campo; os diálogos com os entrevistados sempre se remontavam ao passado, aos deslocamentos espaciais, às sucessivas expulsões de suas terras, à guerra do Chaco, aos parentes que moravam em outros locais. A história é sempre presente para eles, porque muito cheia de significados e definidora de seu presente, e se apresenta como uma consciência aguda de que o presente deles está relacionado com o passado.

\section{Os Chiquitanos}

Segundo Roberto Tomichá Charupá (2008, p. 231), Chiquitano é um termo abrangente e que se refere a todos os povos reduzidos pelos jesuítas nos séculos XVII e XVIII e que, após a expulsão dos 
JOANA APARECIDA FERNANDES SILVA - Pertencimento e identidade, territorialidade...

jesuítas da América Espanhola, em 1754, tiveram modificações importantes tanto em sua configuração social como nos seus processos históricos. Os cerca de vinte e cinco povos originais que foram aldeados pelos jesuítas, em sua maioria, perderam sua especificidade cultural, ou seja, desapareceram enquanto povos singulares, dando lugar aos Chiquitos, termo que os religiosos adotaram para designar os grupos sob o domínio missioneiro. No entanto, alguns segmentos sob o regime jesuítico voltaram a viver nas regiões de florestas e voltaram a ser independentes (RIESTER, 1986; BALZA, 2001).

Três sistemas de trabalho absorveram os Chiquitanos: como peões em fazendas próximas aos aldeamentos, trabalho forçado sob o sistema de enganches por dívidas em seringais nos departamentos de Beni e Pando, na zona cauchera de Ñuflo de Chávez e Velasco ou nas minas de Potosí; no Brasil, como na Bolívia, eles também foram incorporados aos trabalhos em fazendas, e mesmo que sem muito conforto ou pagamentos justos, os fazendeiros locais sempre foram descritos como mais bondosos que os bolivianos; aqui também trabalharam em seringais, mas a atividade predileta, pelos relatos e pela literatura, sempre foi o trabalho com o gado, uma habilidade aprendida nos aldeamentos.

A história dos Chiquitanos, tanto na Bolívia como no Brasil, obedeceu a uma única lógica até recentemente, quando os dois países estabeleceram os últimos acertos na linha da fronteira demarcatória. Até finais da década de 1990 não havia uma separação (a não ser pela distância geográfica, no caso dos que moravam mais distantes) e tampouco uma percepção forte por parte dos Chiquitanos do que era Brasil ou Bolívia. A presença do exército de ambos os lados marcava concretamente a nacionalidade brasileira ou boliviana: roupas, fisionomias e língua eram sinais diacríticos que indicavam onde alguém estava situado, se na Bolívia ou no Brasil. No entanto, à parte da presença militar, rarefeita aliás, não havia muita diferença entre os aldeamentos de um ou outro país; a circulação de pessoas era livre e não raramente membros de uma mesma família moravam uns do lado brasileiro da fronteira e outra parte no lado boliviano, sendo que, em alguns casos, era possível a passagem de um para outro lado todos os 
dias, ou mesmo duas ou três vezes ao dia, se fosse o caso. Em Acorizal e Fortuna, ambas as aldeias próximas à linha demarcatória, por exemplo, havia algumas famílias com parentes próximos em Marco Porvenir e em Ascención, duas localidades também quase encostadas na fronteira física.

Quando perguntado qual a diferença entre a Bolívia e o Brasil, um senhor me respondeu que the parecia que era que no primeiro país se fala o espanhol e, no segundo, o português. Mas, mesmo assim, até recentemente, havia grande número de pessoas que falavam 0 espanhol morando do lado brasileiro ${ }^{6}$. A aquisição apenas do português, sem o espanhol, parece ser um fenômeno muito recente nos locais pesquisados?.

Os jovens Chiquitanos lutaram como soldados na Guerra do Pacífico (1879-1883), na Guerra do Acre (final do século XIX disputa entre Brasil e Bolívia pela região dos seringais), na guerra do Chaco (1932-1935, entre Bolívia e Paraguai) e na Guerra do Paraguai (1864-1870). Pelos relatos colhidos durante trabalhos de campo, a Guerra do Chaco ainda está presente na memória dos mais velhos, inclusive no lado brasileiro. Várias famílias que entrevistamos no Brasil e que no momento da pesquisa moravam relativamente isoladas, sem pertencerem a uma comunidade especifica, tinham se deslocado até onde vivem atualmente fugindo da Bolívia e do exército boliviano, para proteger seus filhos menores, com catorze ou quinze anos, que eram obrigados a lutarem na guerra.

Uma vez que a guerra acabou, continuaram a morar do lado brasileiro da fronteira, afirmando que os patrões - fazendeiros brasileiros - eram melhores, ao passo que os bolivianos eram muito violentos, conforme se mencionou acima.

O fato de algumas famílias terem fugido para o Brasil, no início do século $X X$, quando as fronteiras políticas ainda não estavam totalmente definidas, e de inúmeros trabalhadores dos seringais terem sido Chiquitanos da Bolívia não deve levar à suposição de que todos os Chiquitanos que estão no Brasil são imigrantes e estrangeiros.

\footnotetext{
${ }^{6}$ Esta informação foi coletada durante meus trabalhos de campo no território dos Chiquitanos, tanto no Brasil como através de depoimentos informais na Bolívia. Ela também consta em Balza (2001), que fez um estudo sobre territorialidade no extinto aldeamento de San Jose.

${ }^{7}$ Ao ser perguntado quem ele é, respondeu que é pobre, apenas isso.
} 
JOANA APARECIDA FERNANDES SILVA - Pertencimento e identidade, territorialidade...

Um estudo da documentação jesuítica feita por Tomichá Charupá (e reforçada pelo mapa de Metraux (1948)) mostra que o limite extremo do território ocupado pelos povos que foram aldeados pelos jesuítas era o Rio Guaporé. Portanto, atualmente, Brasil. Mas, observe-se que pelo tratado de Tordesilhas, esta região era totalmente espanhola nem boliviana, nem brasileira, nem portuguesa.

\section{Territorialidades na Bolívia e no Brasil}

Conforme se constatou durante a pesquisa de campo e nas entrevistas, o processo de ocupação territorial dos Chiquitanos após o regime dos jesuítas dava-se através de uma constante mobilização de siblings na região boliviana da Chiquitania e se estendia até as imediações do Rio Paraguai. Os deslocamentos, de acordo com os informantes, eram motivados pela busca de terras melhores, de caça, ou simplesmente de locais mais bonitos. Nos aldeamentos de onde os jesuítas foram expulsos, cidades cresceram (San Miguel, San Inácio, San Jose etc.) e a população remanescente de Chiquitanos passou a ocupar áreas mais periféricas. O que importa em termos da reflexão que se deseja fazer é que a territorialidade deste povo obedeceu a um padrão de mobilidade e expansão constante no interior de fronteiras constituídas através de relações interétnicas.

As comunidades ou aldeias formaram-se a partir desse grupo de siblings; não raro os irmãos já chegavam no local onde desejavam estabelecer-se com seus cônjuges e filhos pequenos; quando estes cresciam, deveriam casar-se, e a regra para o casamento poderia ser endogâmica ao estabelecimento ou endogâmica quanto ao grupo, mas geralmente entre pares de estabelecimentos próximos.

Esta forma de ocupar o território formou redes de relações e de trocas que persistem até os dias atuais. No Brasil estas redes estão organizadas em conjuntos de quatro ou cinco estabelecimentos que podem ser categorizados como núcleos (SILVA, 2008), e estes núcleos relacionam-se com as cidades próximas através de uma outra modalidade de rede, tecida por filhos ou filhas que não puderam continuar vivendo nas aldeias. 
O importante a notar aqui é que a presença da fronteira política entre os dois países, até recentemente, não quebrava a lógica das relações e tampouco a da ocupação territorial estabelecida por redes de sociabilidade e de utilização de recursos naturais. O que delimitava as terras dos Chiquitanos era a maneira como as ocupavam, bem como outros vizinhos indígenas; não era a fronteira brasileira ou boliviana que marcava e definia sua territorialidade.

A expansão das sociedades nacionais, a criação de novas cidades e o aumento do número de fazendas provocou um "sitiamento" dos estabelecimentos dos Chiquitanos. A imagem bastante forte e precisa, expressa por uma mulher entrevistada, é a do tipiti, instrumento de prensar a massa de mandioca (SILVA, 2008).

No momento presente eles estão divididos por uma linha de fronteira que tende a ser cada vez mais controlada e rígida, dificultando os deslocamentos e "deslizamentos" por seu território e sitiados por cidades e fazendas. A periferia dos municípios de Cáceres, Porto Espiridião, Vila Bela e de Pontes e Lacerda, todos em Mato Grosso, abriga atualmente esse contingente dos Chiquitanos expulsos de suas terras, principalmente a partir de 1976, com o processo de titulação de terras, realizada pelo INCRA - Instituto Nacional de Colonização e Reforma Agrária (SILVA et al, 1998).

\section{Ensaio de comparação sobre terras na Bolívia e no Brasil}

As políticas sobre territórios indígenas são tratadas de maneira diferente nos dois países. A Ley del Instituto de Reforma Agrária, promulgada em 1996, na Bolívia, definiu como "terras comunitárias de origem" - TCO - aquelas que

constituyen el hábitat de los pueblos y comunidades indígenas y originarias, a los cuales han tenido tradicionalmente acceso y donde mantienen $y$ desarrollan sus propias formas de organización económica, social y cultural, de modo que aseguran su sobrevivencia y desarrollo. Son inalienables, indivisibles, irreversibles, colectivas, compuestas por comunidades y mancomunidades, inembargables e imprescriptibles (Artigo 41, §5, Ley del Servicio de 
No capítulo VIII da Constituição brasileira de 1988, em seu artigo 231, se reconhece o direito dos índios em terem sua cultura, língua, organização social, tradições e os direitos sobre suas terras. No parágrafo primeiro, as terras tradicionalmente ocupadas são consideradas aquelas

\begin{abstract}
Habitadas em caráter permanente, as utilizadas para suas atividades produtivas, as imprescindíveis à preservação dos recursos ambientais necessários a seu bem-estar e as necessárias a sua reprodução física e cultural, segundo seus usos, costumes e tradições (Constituição da República Federativa do Brasil, cap. VIII, artigo 231, 1988).
\end{abstract}

Nesta mesma Constituição, o Estado reconhece seu dever de demarcar e garantir as terras indígenas. No entanto, os direitos às terras colidem com interesses ligados ao capital, como vem ocorrendo com as terras ocupadas pelos Chiquitanos em Mato Grosso e também na Bolívia. Em Mato Grosso há uma área indígena já reconhecida por decreto e outras contam com portaria para estudo; no entanto, tem sido impossível sua regularização por parte da FUNAl, pois os interesses ligados às empresas agropecuárias são preponderantes.

Embora o texto da definição de terras transcrito logo acima permita pensar que há semelhanças, na prática, essas políticas produzem resultados bem distintos: enquanto no Brasil as terras indígenas a serem demarcadas são objeto de estudos históricoantropológicos para identificá-las e, uma vez uma área identificada, a Fundação Nacional do Índio procura demarcar um local onde seja possível a realização da cultura de uma maneira mais ampla possível; na Bolívia, em função talvez do entendimento de que os pueblos originales sejam campesinos, as terras indígenas ou TCO (Tierras Comunitarias de Origen) seguiram um modelo distinto.

No entanto, apesar da Constituição brasileira assegurar aos índios suas terras tradicionais, as terras que os Chiquitanos ocupam no Brasil são extremamente questionadas e o movimento de expulsão foi muito forte na década de 1990, em função da instalação e ampliação do capital nesta região que ocupam em Mato Grosso. Em resumo, 
eles ainda não têm terras.

$\mathrm{Na}$ Reforma Agrária realizada na Bolívia em 1953, como os Chiquitanos foram tomados por camponeses, as terras que thes foram destinadas seguiram um modelo agrarista, não consideraram as formas de uso e nem que havia um povo com identidade própria, de acordo com Balza (2001, p. 29). A partir da década de 1980, os povos indígenas começam com um vigoroso movimento de defesa de seus direitos e de reivindicação de terras e, a partir de 2009, a nova Constituição boliviana reconhece, em seu artigo terceiro, a pluralidade étnica da nação boliviana, conforme se pode observar:

Artículo 3. La nación boliviana está conformada por la totalidad de las bolivianas y los bolivianos, las naciones y pueblos indígena originario campesinos, y las comunidades interculturales y afrobolivianas que en conjunto constituyen el pueblo boliviano (Nueva Constitución Política Del Estado, 2009).

O termo constitucional para os índios é "pueblos indígenas originarios campesinos", que implica em reconhecer uma ancestralidade no país, mas continua a relação entre índios e camponeses. Sobre as terras indígenas, na constituição de 2007 , são consideradas como territórios, seu Artigo 293 versa que

II. Para conformar uno o más territorios indígenas originario campesinos autónomos que se encuentren en una sola entidad territorial indígena originario campesina autónoma, la ley señalará los mecanismos de constitución, coordinación y cooperación con la entidad territorial correspondiente para el ejercicio de su gobierno.

III. Para conformar un territorio indígena originario campesino autónomo que comprenda a más de una entidad territorial indígena originario campesina autónoma, la ley señalará los mecanismos de articulación, coordinación y cooperación entre estas unidades y la entidad para el ejercicio de su gobierno (Constitución Politica del Estado, Bolivia, 2007).

Poder-se-ia pensar que no Brasil os índios são considerados brasileiros, mas a Bolívia se reconhece como um estado plural 
JOANA APARECIDA FERNANDES SILVA - Pertencimento e identidade, territorialidade...

composto por várias nações e reconhece oficialmente 37 idiomas, entre eles, está a língua falada pelos Chiquitanos, o Bésiro.

\section{Fronteira, identidade e Pertencimento}

Weber (2000) aponta como elemento constituinte da nação e da comunidade étnica o sentimento de pertencimento. Não é o fator biológico que tece o tecido da nação ou que organiza a cultura. Barth (1998) também salientou que a etnicidade emerge do confronto, e que as fronteiras étnicas se estabelecem a partir das relações entre grupos.

Roberto Cardoso de Oliveira (2005) levanta questões de ordem teórico-metodológicas relacionadas a uma antropologia em fronteiras que apontam para o entendimento das relações étnicas, multiculturais e transnacionais que aí ocorrem. Ele sugere que

será num espaço internacional marcado pela
contigüidade de nacionalidades distintas (e no interior
dessas, supostamente, de etnias diversas), que surge
o foco privilegiado de investigação: não mais o
sistema interétnico, mas o sistema inter e
transnacional, visto em termos das nacionalidades em
conjunção (CARDOSO DE OLIVEIRA, 2005, p. 15).

Observa-se que entre os Chiquitanos não há um sentido de pertencimento em geral, mas mostra como, a partir do sibling e de casamentos entre núcleos, estabelecem-se redes que são mais importantes do que o pertencimento a um povo indígena - noção vaga e estranha para eles, uma vez que índio, conforme verificou-se no campo, é um outro que não ele, alguém selvagem que anda nu e atacando quem mora próximo. É provável que na Bolívia possa ocorrer fenômeno semelhante, pois a Chiquitania designa uma região inteira, que inclui fazendas, cidades, os aldeamentos, vilas e a identificação com o povo Chiquitano pode ser vaga também. Possivelmente os jogos identitários passem por pertencimento a lugares (San Inácio, Santa Ana, San Miguel ou inaciano, anenho, miguelenho etc.) e pelas redes constituídas de famílias e amigos, festas de santo, mercados etc. 
JOANA APARECIDA FERNANDES SILVA - Pertencimento e identidade, territorialidade...

A adjetivação de "povos originais", que deve designar a população indígena boliviana, instituída a partir de políticas públicas de garantia da terra, provavelmente também diz muito aos Chiquitanos da Bolívia. Embora histórico, o conceito de campesino (camponês) tampouco, uma vez que este é um conceito extremamente estrangeiro a eles.

A herança jesuítica é fortíssima na Bolívia, enquanto no Brasil é mais apagada. Em ambos locais a religiosidade permanece forte, mas na região da Chiquitania, os ritos católicos, nas áreas urbanas, antigos aldeamentos jesuíticos, permanecem com muita força.

Se no Brasil há uma enorme diversidade de povos indígenas, na Bolívia há uma forte separação entre os povos da montanha, ou andinos - Aimara e Quéchua -, e os povos da planície, onde há uma diversidade étnica maior. Há ainda o enorme preconceito expresso pela palavra camba, cujo sentido pode ser o de índio preguiçoso, mas a depender do contexto é sinônimo de certa nobreza. No Brasil a adjetivação de bugres é extremamente ofensiva e subalternizante.

Refletindo a multiplicidade de situações na fronteira, e pensando nela como um lugar de múltiplas significâncias, de intensa convivência cultural, esta é a identidade dos Chiquitanos. Fluida, móvel, como qualquer outra identidade social ou étnica, no entanto, revestida de uma enorme complexidade forjada a partir de uma história de lutas, conflitos entre duas coroas, primeiramente, entre índios e missionários, participação em guerra, fuga do exercito, perseguição, despossuimento, expulsão da terra.

Mas a identificação externa, a de bugres, é ofensiva aqui, como é ofensiva a de camba lá. Na Bolívia também este parece ser um elemento importante na identificação dos Chiquitanos. Por exemplo, em Balza (2001), pode-se observar o seguinte depoimento:

Antes la gente blanca dava guasca a la gente humilde, o sea, a nosotros los chiquitanos. Como había gente rica, al que no queria trabajar le obligavan y antes reinava la guasca y por eso nos salimos (BALZA, 2001, p. 199).

Não é, portanto, a etnicidade o aspecto priorizado como identificador. Ao contrário, como Ema Cintra (2008) demonstrou, as 
identidades dos Chiquitanos são silenciadas e no silêncio eles buscam invisibilisar-se para melhor sobreviver. Mas, pelo menos no lado brasileiro, há controvérsias entre os Chiquitanos. Após o reconhecimento, por parte da FUNAI, da etnicidade deste povo, nem todos em Fazendinha e Acorizal concordaram com a tutela. Conflitos têm sido frequentes com algumas famílias que se afirmam categoricamente como não índios.

Há controvérsias também na política estadual e nos municípios próximos às aldeias: em Silva (2008), foi estudada a manipulação de identidades no lado brasileiro em Mato Grosso, sobretudo no que se refere à identificação externa. Neste caso a fronteira também é utilizada como um argumento sobre o perigo antevisto pela demarcação de áreas indígenas brasileiras. $\mathrm{O}$ argumento de políticos é de que demarcar terras nesta região a deixaria mais vulnerável.

Há um emaranhado no que diz respeito à identificação externa para os Chiquitanos no Brasil, pois o racismo é uma conduta recorrente e xenofobia encobre as relações raciais: o outro é negado e a distinção é buscada no argumento de que os Chiquitanos são imigrantes estrangeiros. A explicação da distinção, após o reconhecimento da indianidade dos Chiquitanos pela FUNAI, foi deslocada entre os regionais para a história remota de que eles seriam bolivianos que teriam imigrado para o Brasil. Na Bolívia, como de certa forma se reconhece o direito aos "pueblos originales", a xenofobia não ocorre, embora, evidentemente, o termo indígena tenha uma carga muito pesada para os que assim são identificados. Como em outras localidades, em outros países, índio simboliza atraso e preguiça.

Voltando ao Brasil, a ideia do fundamentalismo de cada um em seu lugar, de uma maneira estranha, alia-se ao racismo. Se no fundamentalismo os direitos podem ser reconhecidos, mas não no compartilhamento do território, pois que os Chiquitanos são de outro lugar, no racismo há uma hierarquização (STOLKE, 1993).

Dois níveis se entrecruzam: o da ação e o das representações. $\mathrm{Na}$ ação incide mais diretamente o racismo, que os define como inferiores; nas relações de trabalho há uma convivência, até certo ponto, pois as mulheres que trabalham como empregadas e os 
homens que trabalham nas fazendas, cuidando de pastos, manejando gado e trabalhando na agricultura. $O$ termo bugre hierarquiza claramente os homens e mulheres que são a força de trabalho na região, mal remunerada e pouco considerada como útil. Enquanto representação social, compartilhada pela população regional e políticos locais, a palavra bugre perdeu força para a ideia de imigrante. Agora sim, uma representação mais perigosa, pois exclui dos direitos as terras que sempre ocuparam e a cidadania.

Percebe-se que não é possível polarizar a identidade dos Chiquitanos em apenas duas: ou índio e branco, ou bugre e civilizado, ou imigrante e brasileiro, ou boliviano e brasileiro. Há um jogo de identidades que são reveladas ou silenciadas, dependendo do contexto político, das localidades e das inter-relaçõs entre os mesmos Chiquitanos ou das relações entre estes e os não índios.

Baines (2003) observou que a situação na fronteira internacional, onde vivem os Makuxi e os Wapichana, na fronteira entre Guiana e Brasil,

$$
\begin{aligned}
& \text { aponta para a complexidade da atuação de } \\
& \text { identidades étnicas no nível local que coexistem com } \\
& \text { identidades nacionais que se remetem aos estados } \\
& \text { nacionais, situações repletas de contradições e } \\
& \text { ambigüidades. A etnicidade e a nacionalidade se } \\
& \text { sobrepõem e são acionadas em contextos que } \\
& \text { expressam a organização política dos povos indígenas } \\
& \text { nesta região de fronteira, num sistema inter e } \\
& \text { transnacional, visto em termos das nacionalidades em } \\
& \text { conjunção (...) (BAINES, 2003, p. 16). }
\end{aligned}
$$

A autoidentificação imperante no Brasil, entre os Chiquitanos, foi de apenas pobre. Oposição mais universal do que todas as demais: pobre e rico. Oposição que situa e posiciona dois polos em conflito independentemente da etnicidade e da nacionalidade.

\section{Referências bibliográficas}

APPIAH, Anthony. In my father's house: Africa in the philosophy of culture. Oxford: Oxford University Press, 1992.

BAINES, Stephen, Os Índios Makuxi e Wapichana e suas relações com Estados 
Nacionais na fronteira Brasil-Guiana. Brasília: UNB, 2003. (Série Antropologia, $\mathrm{n}$. 338).

BALZA, Roberto Alarcon. Tierra, território y territorialidad: un estudio antropológico sobre la evolución en las formas de ocupación del espacio del pueblo indígena chiquitano de la ex-reducción jesuita de San José, Série Pueblos Indigenas de las Tierras Bajas de Bolivia. Santa Cruz de La Sierra: APCOB/SNU/ IWGIA, 2001. v. 17.

BARTH, Fredrik. Grupos étnicos e suas fronteiras: In: POUTIGNAT, Philippe; STREIFF-FENART, Jocelyne (Org.). Teorias da etnicidade. São Paulo: Editora da Unesp, 1988. p. 25-67.

BOLÍVIA. Constitución de Bolivia de 2007. Disponível em: www.stf.jus.br/.../NUEVACONSTITUCIONDEB . Acesso em: 30 jun. 2012.

. Nueva Constitución Política del Estado de Bolívia. 2010. Disponível em: http://www.ernestojustiniano.org/2008/10/nueva-constitucion-politica-del-estado- debolivia/ . Acesso em: 29 mar. 2010.

Ley del Servicio de Reforma Agraria (Ley N. 1715 de 18 de octubre de 1996). Disponível em: http://www.elaw.org/node/2673 . Acesso em: 30 jun. 2012.

BRASIL. Constituição da República Federativa do Brasil de 1988. Disponível em: http://www.planalto.gov.br/ccivil_03/constituicao/constituicao.htm . Acesso em: 30 jun. 2012.

CARDOSO DE OLIVEIRA, Roberto. Introdução. In: CARDOSO de OLIVEIRA, Roberto; BAINES, Stephen (Orgs.). Etnicidade e nacionalidade em fronteiras. Brasília: UnB, 2005. p. 8-20.

CARDOSO de OLIVEIRA, Roberto; BAINES, Stephen (Orgs.). Etnicidade e nacionalidade em fronteiras. Brasília: UnB, 2005.

CHARUPÁ, Roberto Tomichá. La primera evangelización en las reducciones de Chiquitos, Bolivia, 1691-1767. Cochabamba: Editorial Verbo Divino/UCB, 2002.

La formación socio-cultural de los Chiquitanos en el Oriente Boliviano (siglos XVI-XVIII). In: SILVA, Joana F. Estudos sobre os Chiquitanos. Goiânia: Editora da Universidade Católica de Goiás, 2008. p. 43-60.

CINTRA, Ema Dunck. Vozes Silenciadas: um estudo Sociolinguiístico dos Chiquitano do Brasil. In: SILVA, Joana F. Estudos sobre os Chiquitanos. Goiânia: Editora da Universidade Católica de Goiás, 2008. p. 27-42.

MALDI, Denise. Vistoria na Fazenda Nacional de Casalvasco (Fundação Nacional do Índio). Ordem de serviço n. 134/95, Administração Regional de Cuiabá, GT, 1995.

Espaço Ameríndio, Porto Alegre, v. 6, n. 1, p. 119-137, jan./jun. 2012. 
JOANA APARECIDA FERNANDES SILVA - Pertencimento e identidade, territorialidade...

MEIRELES, Denise Maldi. Guardiães da Fronteira: Rio Guaporé, século XVIII. Petrópolis: Vozes, 1989.

METRAUX, Alfred. The Chiquitoans and other tribes of the Province of Chiquitos tribes of Eastern Bolivia and the Madeira Headwaters. In: STEWARD, Julian H. Handbook of South American Indians: the tropical forest tribes. Washington: United States Government Printing Office, 1948. v. 3. p. 78-89.

RADDING, Cynthia. Landscapes of power and identity: comparative histories in the Sonoran Desert and the Forests of Amazonia from Colony to Republic: Duke: U. Press, 2006.

RIESTER, Jurgen. La Chiquitania: visión antropológica de una región en desarrollo. Cochabamba/La Paz: Editorial Los Amigos del Libro, 1986. Tomo 1.

RONDON, Major Frederico. Na Rondônia Ocidental. São Paulo: Companhia Editora Nacional, 1936.

SILVA, Joana A. F. et al. Estudo das Comunidades Indígenas na Área de Influência do Gasoduto Bolívia-Mato Grosso. Cuiabá, 1998. [mimeo].

SILVA, Joana, A. F. Relatório Circunstanciado de Identificação da Terra Indígena Chiquitano, 2004, Funai, Portaria: 1187/PRES., de 11 de novembro de 2002, do presidente da FUNAI/ Ministério da Justiça e publicada no Diário Oficial da União em 13/11/2002.

Identidades e conflito na fronteira: poderes locais e os Chiquitanos, memória americana, Mem. am. n. 16-2 Ciudad Autónoma de Buenos ires jul./dic. 2008.

STOLKE, Verena. Cultura Européia: uma nova retórica da exclusão? Revista Brasileira de Ciências Sociais, São Paulo, v. 8, n. 22, p. 20-31, 1993.

WEBER, Max. Economia e sociedade: fundamentos da sociologia compreensiva. Brasília: Ed. UnB, 2000.

Espaço Ameríndio, Porto Alegre, v. 6, n. 1, p. 119-137, jan./jun. 2012. 